\title{
Endoscopic treatment of a third ventricle choroid plexus cyst
}

\author{
Danielle de Lara, M.D., Leo F. S. Ditzel Filho, M.D., Jun Muto, M.D., and Daniel M. \\ Prevedello, M.D. \\ Department of Neurological Surgery, The Ohio State University, Columbus, Ohio
}

\begin{abstract}
Choroid plexus cysts are frequent benign intraventricular lesions that infrequently cause symptoms, usually in the form of obstructive hydrocephalus. These instances are even less common in the adult population. When warranted, treatment seeks to reestablish cerebrospinal fluid flow and does not necessarily require resection of the cyst itself. Hence, endoscopic exploration of the ventricles with subsequent cyst ablation is the current treatment of choice for these lesions.

Herein we present the case of a 25 -year-old female patient with a 3-week history of intermittent headaches. Investigation with computerized tomography $(\mathrm{CT})$ of the head detected supratentorial hydrocephalus, with enlargement of the lateral and third ventricles. Magnetic resonance imaging revealed a homogeneous cystic lesion in the third ventricle. A right-sided, pre-coronal burr hole was carried out, followed by endoscopic exploration of the ventricular system. A third-ventriclostomy was performed. With the aid of the 30-degrees endoscope, a cyst arising from the choroid plexus was visualized along the posterior portion of the third ventricle, obstructing the aqueduct opening. The cyst was cauterized until significant reduction of its dimensions was achieved and the aqueduct opening was liberated. Postoperative recovery was without incident and resolution of the hydrocephalus was confirmed by CT imaging. The patient reports complete improvement of her headaches and has been uneventfully followed since surgery.

The video can be found here: http://youtu.be/XBtj_SqY07Q.

(http://thejns.org/doi/abs/10.3171/2013.V1.FOCUS12332)
\end{abstract}

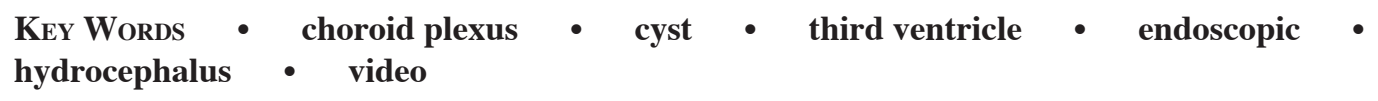

Manuscript submitted October 2, 2012.

Accepted November 2, 2012.

Please include this information when citing this paper: DOI: 10.3171/2013.V1.FOCUS12332.

Address correspondence to: Daniel M. Prevedello, M.D., The Ohio State University, Department of Neurosurgery, N-1011 Doan Hall, 410 W. 10th Avenue, Columbus, OH, 43210. email: Daniel. prevedello@osumc.edu.. 